\title{
MOTIVATING EMPLOYEES OF THE HIGHER EDUCATION INSTITUTON: CASE STUDY OF ACADEMIC TEACHERS
}

\author{
Sylwia Stachowska1, Iwona Zofia Czaplicka-Koztowska \\ ${ }^{1}$ Researcher, PhD, University of Warmia and Mazury in Olsztyn, Poland. \\ E-mail sylwia.stachowska@uwm.edu.pl \\ ${ }^{2}$ Researcher, PhD, University of Warmia and Mazury in Olsztyn, Poland. \\ E-mailiwona.kozlowska@uwm.edu.pl
}

One of the most significant managerial functions is motivating which leads to the implementation of the particular organizational objectives, to shaping of engagement and loyalty of its members and, consequently, to the raising effectiveness of their actions. The properly constructed solutions in the area of employee motivating process may result in the several benefits for the organization, which is true also for the public institutions including the academic ones, which employ a specific group - academic teachers. The aim of the herein study was the identification of the factors which have an impact on the motivation of academic teachers employed in the higher education institution. The research was conducted with the questionnaire survey among the academic employees of the University of Warmia and Mazury in Olsztyn, Poland. The conducted survey concludes that the motivation of employees is affected by various factors, mostly concerning the remuneration for work and also with the self-development possibilities, stability of employment, interpersonal relations, and effective communication. It is vital and worth to use the knowledge about them for improving the quality and efficiency of the organization.

Keywords: human resources management, employee motivation, public organization, academic teachers

JEL Codes: H83, J24, M12.

\section{Introduction}

Motivating is one of the most important functions of the organization's management and the ability to motivate is considered one of the most significant managerial skills. Achieving the satisfying results at work and other activities depends above all on the motivation to take action, and the proper corresponding impact on the employee motivation leads to the achievement of the organization's specific objectives, contributes to shaping the loyalty of its members, as well as to raising their level of performance and commitment (Stachowska, 2013). The notion of motivating is understood as 'the process of conscious and deliberate influence on the behaviour of people in the work process by creating conditions to enable them to meet the needs as a result of their contribution to the specific objectives of the organization' (Pocztowski, 2007). In other words, motivation to work is a process of deliberate and intentional impact on employee motivation by providing resources and opportunities to meet their expectations and develop values to achieve the objectives assumed by the motivating subject, taking into account the environment of both sides of the process (Borkowska, 2006).

Motivating involves associating goals (expectations and values) of the employee and the organization. Therefore, it should enable the employees to 
participate in the activities of the organization and provide them with the commitment to work using the professional potential to achieve the objectives of the organization. The achievement of the objectives of the motivator is possible through the creation of resources and the feasibility of values and expectations of the motivated (Borkowska, 2006). Therefore, it is necessary to identify the needs and expectations of employees and individualized approach to them for the effectiveness of the motivating incentives.

There is a wide range of opportunities to stimulate and reinforce the motivation for work. The management can operate with a variety of different motivators, for instance induce higher motivation through creation of higher salary, but also the interest in the professional duties by creating the prospects for promotion, more favourable non-salary benefits, better working conditions, more opportunities to participate in the management of company, greater freedom of action by expanding selection opportunities, etc. The tools of motivation always have a big impact on the behaviour of people in the organization - they shape employees' awareness, attitudes to work and towards the superiors, as well as mutual relations. The motivating factors encourage people to take more ambitious tasks, improve the quality of the performer tasks and qualifications, omission of passive attitude and accepting the commitment and willingness to cooperate (Penc, 1996).

It should be remembered that the choice of proper (effective) means of motivation requires implementation of the employees' evaluation system which takes their work expectations into account. (Pietron'-Pyszczek, 2004). The level and the diversification of the expectations result from, e.g. individual potential and sources of an employee's motivation, as well as their attitude (reaction) towards the organizational system of rewards and penalties. (Pietron-Pyszczek, 2015). The impact of motivational stimulus may be more effective when there is a deep understanding thereof and adaptation to the specific situations (Sekuła, 2008).

It should not be forgotten, that the motivating process within the organization occurs in close association with its environment (socio-economic system of the country, legal norms, conditions of political and socio-cultural nature), but above all in close relations to the internal factors such as the size of the organization, type and nature of its business, organizational structure, organization of work, the level of technology used, market position, physical working conditions and organizational climate.

The issue of motivating employees affects any organization, including the public and higher education institutions. The currently implemented tasks in the public organizations which are requiring creativity and involvement of employees (Czajka, 2012) confirm, in line with the postulates of New Public Management, incorporating professional management implementation (Hood, 1991), the importance of human capital for the effective functioning of such organizations. The increase in efficiency and effectiveness can be achieved, among others, by the improvement of the motivation procedures (Ściborek, 2014). In such organizations, where the quality of work is significantly dependant on the engagement of the 
employees, achieving the proper level of motivation becomes an exceptional challenge (Długosz, 2006).

The sources of motivation of employees of public organizations can be of the same nature as in the case of the employed in the private sector, but their hierarchy and influence may be different (Buelens, Van den Broeck, 2007). As in the case of employees of other organizations, an important role in may be attributed to the financial factor. The studies have shown that the public employees are motivated to a greater extent compared to private sector employees by the content of the work, personal development and security (Pauli, Sapeta, 2016).

A higher education institution is a specific type of an organization. As operating within the area of non-material services, human resources may be stated the most significant factor determining its market success (Geryk, 2010). The higher education institution is a unique employer of, inter alia, academic teachers. This occupational group requires an exceptional approach in terms of work motivation. Therefore, it seems crucial to differentiate the factors, which influence the efficiency of the motivation process within this area.

It must be remembered, that in case of higher education institutions the motivation solutions are largely influenced by the environment, with the legal determinants in particular. It may be noticed, that the legislation duress supersedes the motivation imperative (Warwas, Wiktorowicz, Gzik, 2017). According to the thesis formulated in the documentation of the Ministry of Science and Higher Education (2010), the motivation system operating in higher education institutions is practically non-existent, whereas the introduced motivation measures do not fulfil their requirements. Therefore, the implementation of an efficient motivation system, which incorporates material and non-material factors, has become a necessity. The creation of the system requires opinion and expectations research focused both on non-academic employees and academic teachers, as the latter play a key role for the institution's operational goals achievement, mainly in the quality execution of the education process.

The actions aiming to improve the quality of human resources management, to increase the degree of identification with the organization and commitment, job satisfaction and motivation, are necessary for elevating the quality of operation of those organizations, the increase of effectiveness, creativity and employee initiative. From the point of view of the effectiveness of these measures it is important to understand the factors that determine the motivation of employees in the job environment.

Copyright (C) 2019 The Authors. Published by Vytautas Magnus University. This is an open-access article distributed under the terms of the Creative Commons Attribution-NonCommercial 4.0 (CC BY-NC 4.0) license, which permits unrestricted use, distribution, and reproduction in any medium, provided the original author and source are credited. The material cannot be used for commercial purposes. 


\section{The purpose and methodology of herein research}

The aim of the study was to identify the factors influencing the motivation of employees of a higher education institution ${ }^{1}$. The research for implementing the assumed objectives was conducted through the questionnaire method and were carried out on a group of academic staff of the University of Warmia and Mazury in Olsztyn, in the academic year of 2016/2017. The analysis was conducted on the 504 correctly completed questionnaires (which accounted for $26.1 \%$ of a total employment in the analysed group of employees of the examined university).

Within the structure of the population the male respondents fractionally dominated in the surveyed population (54.2\%). More than a half of the interviewees (51.8\%) aged 34-49 years, the second largest group were employees over 50 years old $(34.9 \%)$, whereas the last group of $13.3 \%$ constituted employees up to 33 years old. More than a half of the respondents $(53.4 \%)$ had work experience at the University of Warmia and Mazury exceeding 15 years $(25.4 \%$ of the group has declared work for over 25 years), $34.3 \%$ has work experience of 5 up to 15 years, whereas the smallest group of $(12.3 \%)$ declared up to 5 years of work in the researched institution. The most numerous group of academic employees constitutes $79.2 \%$, the remaining respondents either focused on scientific $(12.7 \%)$ or didactic $(8,1 \%)$ activity. In terms of academic degrees, doctors dominated the research (52.8\%), assistant professors, Ph.D. (22.2\%), masters (13.1\%) and professors (11.9\%). More than a half of the respondents (50.8\%) were employed as adjuncts, $16.3 \%$ were associate professors, $14.5 \%$ - assistants, $10.1 \%$ lecturers and senior lecturers and $8.3 \%$ professors. The managerial positions were held by $19.3 \%$ of the respondents.

\section{Research findings}

The respondents claimed that the most significant motivation factor was the level of obtained remuneration $(68.5 \%)$. The other preferred motivators among the surveyed population encompass: stability and safety of employment (53.6\%),

\footnotetext{
${ }^{1}$ The presented study constitute a part of a broader research aiming to identify the opinions of the employees of University of Warmia and Mazury in Olsztyn on the current system of human resources management in the organization as well as their expectations concerning the motivational system. The study was conducted within the works of the Group for development of HRM system at the University of Warmia and Mazury in Olsztyn. The questionnaire was conducted via the system Ankieter, the internal feature within the virtual Academic Students' Evaluation System (USOS). The employees forming the surveyed group received a link to the questionnaire with inquiry to fill the answers electronically. Simultaneously, there was a possibility to fill the questionnaire in paper. Both aforementioned methods guaranteed a full anonymity for the respondents. The survey included questions serving the implementation of the main goal. The questions from the first part of the survey concerned the opinion of employees about six separate areas: attitude towards work and organization, learning and development, relations with superiors, communication and cooperation, organization of work, reward and motivation. The questions from the second part concerned the identification of factors affecting the motivation of employees, including the most valuable incentives, fringe benefits, recognition and demotivating factors, for the respondents. The last part of a survey encompassed the questions about the effectiveness of currently used solutions in the motivation system and the elements that should be reconsidered for the improvement of the incentive system. The survey was designed with the system of cafeteria, giving a possibility to add own answers.
} 
financial benefit, salary increase, bonuses $(49.2 \%)$, convenient working hours (48.6\%), working atmosphere, relations with the colleagues and superiors (45.8\%), freedom of action (44.4\%), working conditions (42.9\%) (Table 1). On the other hand, the motivators of the least impact appeared to include: work organization (25.4\%), superior's approval, letter of congratulation, award diploma, etc. (24.4\%) additional non-salary benefits $(18.3 \%)$.

Table 1. The most significant motivation factors according to the surveyed group of academic teachers

\begin{tabular}{|c|l|c|c|}
\hline \multirow{2}{*}{ No. } & \multicolumn{1}{|c|}{ Specification } & \multicolumn{2}{|c|}{ Answers } \\
\cline { 3 - 4 } & & $\begin{array}{c}\text { No. of } \\
\text { responses }\end{array}$ & $\%$ \\
\hline 1. & Level of obtained remuneration & $\mathbf{3 4 5}$ & $\mathbf{6 8 . 5}$ \\
\hline 2. & Stability and safety of employment & $\mathbf{2 7 0}$ & $\mathbf{5 3 . 6}$ \\
\hline 3. & Financial benefit, salary increase, bonuses & $\mathbf{2 4 8}$ & $\mathbf{4 9 . 2}$ \\
\hline 4. & Convenient working hours (flexitime) & $\mathbf{2 4 5}$ & $\mathbf{4 8 . 6}$ \\
\hline 5. & Quality of relations with the superiors and colleagues & $\mathbf{2 3 1}$ & $\mathbf{4 5 . 8}$ \\
\hline 6. & Possibility of independent action & $\mathbf{2 2 4}$ & $\mathbf{4 4 . 4}$ \\
\hline 7. & $\begin{array}{l}\text { Working conditions (working station equipment and the availability } \\
\text { of needed resources) }\end{array}$ & $\mathbf{2 1 6}$ & $\mathbf{4 2 . 9}$ \\
\hline 8. & Possibility of skills' and professional development & 190 & 37.7 \\
\hline 9. & Possibility of self-fulfilment at work & 190 & 37.7 \\
\hline 10. & Clear criteria for work assessment and promotion & 160 & 31.7 \\
\hline 11. & Prestige of position and workplace & 139 & 27.6 \\
\hline 12. & Work organization & 128 & 25.4 \\
\hline 13. & Non-financial recognition from the superiors (e.g. praise, a diploma, \\
& a letter of congratulation, etc.) & 123 & 24.4 \\
\hline 14. & $\begin{array}{l}\text { Additional non-salary benefits (e.g. vouchers, recreation subsidies, } \\
\text { tickets for cultural events etc.) }\end{array}$ & 92 & 18.3 \\
\hline
\end{tabular}

Source: authors' original calculations based on the results of the conducted survey

The respondents were also asked about the most appreciated additional benefits used at the University of Warmia and Mazury in Olsztyn. According to the opinion of the interviewees, the most valuable and significant working benefits include participation in seminars and conferences (70.2\%), which seems to be coherent with the character of their work. More than a half of the respondents $(56.9 \%)$ named also the course and other forms of employees self-development allowance, and further cofinancing of holidays or covering their cost (39.7\%) and low-interest loans (38.3\%). The survey depicted the least appreciated additional benefits and among them: financing for sports sections $(6.2 \%)$, integrating social events $(6 \%)$, mobile phone (5.4\%), recreational trips and picnics $(5,8 \%)$ (Picture 1$)$.

The respondents were also asked to indicate the most appreciated intangible means of recognition in line with the individual perception. It must be noted, that compared to the previous questions concerning the most important means of motivation, there were significantly fewer answers - less than a half of the 
respondents answered questions about the means of recognition. This may indicate that the surveyed group pays less attention to such factors.

According to the opinions of the interviewees the most significant means of recognition encompass convenient working hours, which was indicated by $45.6 \%$ of the surveyed population (Table 2). The next one was the possibility of participation in an attractive, individually chosen training or conference (45\%). The following were: providing better working tools and equipment $(41.3 \%)$, greater autonomy at work (36.1\%), awards and medals for the service, etc. (35.9\%) as well as letters of congratulation, diploma of recognition (34.9\%). The invitation to the restaurant for lunch or dinner with the supervisor was recognized the least valuable (3\%).

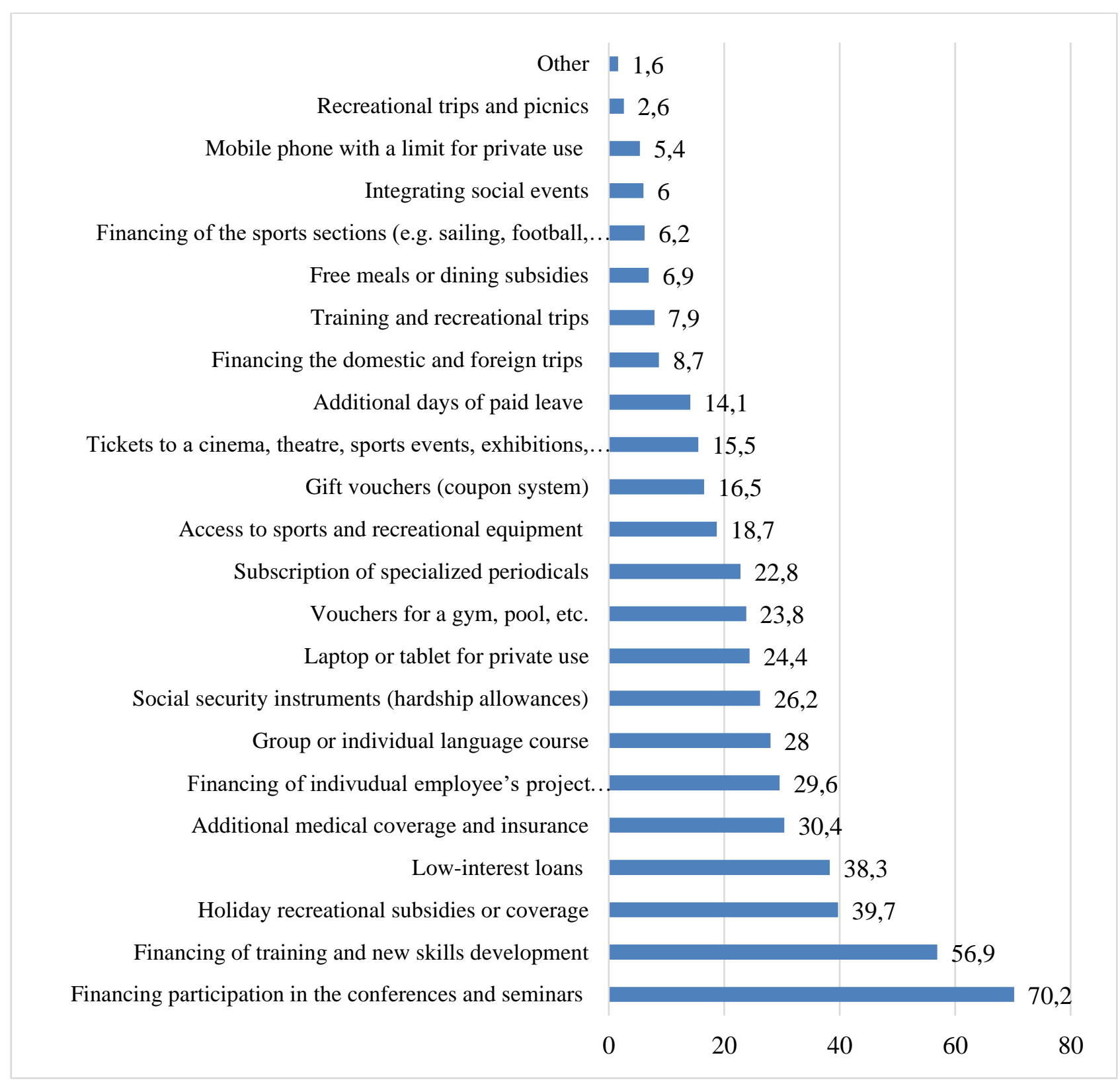

Picture. 1. The most appreciated additional benefits according to the surveyed group of academic teachers

Source: authors' original calculations based on the results of the conducted survey 
Table 2. The most appreciated intangible means of recognition according to the surveyed group of academic teachers

\begin{tabular}{|l|l|c|c|}
\hline \multirow{2}{*}{ No. } & \multicolumn{1}{|c|}{ Specification } & \multicolumn{2}{c|}{ Answers } \\
\cline { 3 - 4 } & & $\begin{array}{c}\text { No. of } \\
\text { responses }\end{array}$ & \% \\
\hline 1. & Convenient working hours & $\mathbf{2 3 0}$ & $\mathbf{4 5 . 6}$ \\
\hline 2. & $\begin{array}{l}\text { Participation in an attractive individually chosen training or } \\
\text { conference }\end{array}$ & $\mathbf{2 2 7}$ & $\mathbf{4 5 . 0}$ \\
\hline 3. & Greater autonomy at work & $\mathbf{2 0 8}$ & $\mathbf{4 1 . 3}$ \\
\hline 4. & Public praise on the forum of the working group & 182 & 36.1 \\
\hline 5. & Awards and medals for the service & 181 & 35.9 \\
\hline 6. & Letter of congratulation, diploma of recognition & 176 & 34.9 \\
\hline 7. & Public praise on the forum of the working group & 116 & 23.0 \\
\hline 8. & Public praise on the forum of whole staff & 76 & 15.1 \\
\hline 9. & $\begin{array}{l}\text { Placing information about the distinguished employees in the } \\
\text { bulletins, corporate newsletters, notice boards, etc. }\end{array}$ & 72 & 14.3 \\
\hline 10. & $\begin{array}{l}\text { The invitation for the employee and the accompanying person to the } \\
\text { unique cultural, artistic or sports event }\end{array}$ & 51 & 10.1 \\
\hline 11. & $\begin{array}{l}\text { Distinction of e.g. honouring with a title of ,employee of the year” } \\
\text { etc. }\end{array}$ & 48 & 9.5 \\
\hline 12. & $\begin{array}{l}\text { The invitation to the restaurant for lunch or dinner with the } \\
\text { supervisor }\end{array}$ & 15 & 3.0 \\
\hline
\end{tabular}

Source: authors' original calculations based on the results of the conducted survey

The high level of bureaucracy was noted as the most significant, demotivating factor according to the majority of the respondents (69\%) (Table 3). The following ones were: remuneration, which most interviewees reported as inadequate to the amount of work and their contribution (50.6\%), low (49.0\%) as well as the insecurity of employment (42.3\%).

Table 3. The most important demotivating factors according to the surveyed group of academic teachers

\begin{tabular}{|l|l|c|c|}
\hline \multirow{2}{*}{ No. } & \multicolumn{1}{|c|}{ Specification } & \multicolumn{2}{|c|}{ Answers } \\
\cline { 3 - 4 } & & $\begin{array}{c}\text { No. of } \\
\text { responses }\end{array}$ & $\%$ \\
\hline 1. & High level of bureaucracy & $\mathbf{3 4 8}$ & $\mathbf{6 9 . 0}$ \\
\hline 2. & Remuneration inadequate to the amount of work and contribution & $\mathbf{2 5 5}$ & $\mathbf{5 0 . 6}$ \\
\hline 3. & Low remuneration & $\mathbf{2 4 7}$ & $\mathbf{4 9 . 0}$ \\
\hline 4. & Insecurity of employment & $\mathbf{2 1 3}$ & $\mathbf{4 2 . 3}$ \\
\hline 5. & Lack of pay rise possibilities & 184 & 36.5 \\
\hline 6. & Lack of clear correspondence between the work and & 174 & 34.5 \\
\hline 7. & Unclear remuneration rules & & \\
\hline 8. & Underestimation of successes, lack of commitment appreciation & 171 & 33.9 \\
\hline 9. & Work overload & 167 & 33.5 \\
\hline 10. & Stress overload & 163 & 33.1 \\
\hline
\end{tabular}




\begin{tabular}{|c|l|c|c|}
\hline 11. & $\begin{array}{l}\text { Lack of team cooperation, support, unsatisfactory work } \\
\text { atmosphere }\end{array}$ & 159 & 31.5 \\
\hline 12. & Malfunction of the information flow & 152 & 30.2 \\
\hline 13. & Malfunction of the work process organisation & 121 & 24.0 \\
\hline 14. & Lack of superiors' support & 119 & 23.6 \\
\hline 15. & Unequal treatment by the superiors & 113 & 22.4 \\
\hline 16. & Bad relations with the superiors & 111 & 22.0 \\
\hline 17. & Bad communication with the colleagues & 111 & 22.0 \\
\hline 18. & Unclear expectations and work assessment criteria & 94 & 18.7 \\
\hline 19. & Lack of initiative support & 88 & 17.5 \\
\hline 20. & Lack of promotion and career path opportunities & 72 & 14.3 \\
\hline 21. & Lack of or limited professional development opportunities & 58 & 11.5 \\
\hline 22. & Unredeemed arrangements concerning professional duties and & 42 & 8.3 \\
\hline 23. & Low autonomy of work & & \\
\hline 24. & Heavy penalties for minor faults & 29 & 8.3 \\
\hline
\end{tabular}

Source: authors' original calculations based on the results of the conducted survey

According to the majority of respondents, setting clear rules for remuneration and rewarding system for employees $(68.7 \%)$ is the most significant element that should be given special attention during the development of motivation system (Picture 2). Almost $40 \%$ of respondents also indicates an attractive system of nonsalary benefits and clear criteria for work assessment. The participants of the survey appreciate improving communication and information flow (37.3\%) and increasing the opportunities for development and promotion (3.5\%).

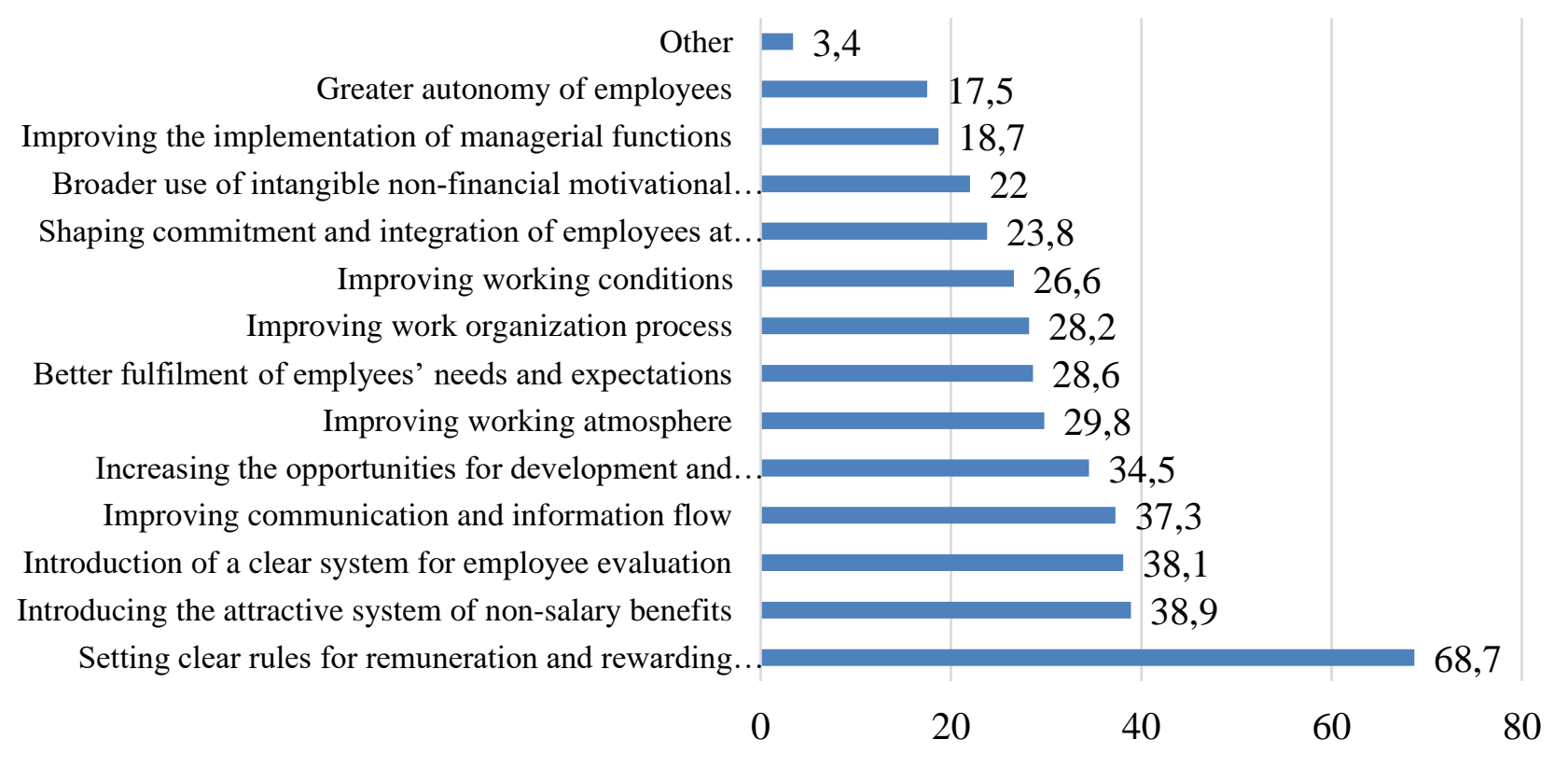

Picture 2. Elements that should be given special attention during the development of motivation system according to the surveyed group of academic teachers (\%)

Source: authors' original calculations based on the results of the conducted survey 


\section{Conclusions}

The knowledge of factors determining employees' motivation is important for the effective management of human resources and the understanding of these elements can enable the organizations to construct and implement the solutions that support the employee engagement. This includes the higher education institutions, where effective motivation of academic teachers should influence the quality of the service and increase the work performance.

The results of the survey allow to construct the following conclusions:

1. The most valuable motivational factors in the opinion of the surveyed academic teachers are primarily financial incentives such as the level of the obtained remuneration, next stability and safety of employment, financial rewards, pay raise or bonuses. Further factors of motivational impact were the intangible elements: flexible working hours, the quality of relationship with the superiors and colleagues, greater autonomy of work and working conditions.

2. The most appreciated additional benefits, according to the respondents, encompass: financing participation in the conferences and seminars as well as financing of training and new skills development, which is coherent with the work characteristics and respondents' aspirations in terms of professional development.

3. Compared to the previous areas, the participants of the survey indicated less interest in intangible means of recognition. Among these the most appreciated ones were: flexible working hours, participation in an attractive individually chosen training or conference and providing better working tools and equipment.

4. According to the majority of respondents, the high level of bureaucracy was the most significant demotivating factor. The following ones regard financial areas and relate mainly remuneration, which is found inadequate to the complexity of work and contribution. Also, the uncertainty of employment is indicated as a significant demotivating factor.

5. The most significant element that should be given special attention during the development of motivation system according to the surveyed population is setting clear rules for remuneration and rewarding system for employees. Further elements include: implementation of the attractive system of non-salary benefits and work assessment, improvement of the communication and information flow as well as increasing the opportunities for development and promotion.

The results of the survey indicate the necessity for improvement of the motivational system dedicated to academic teachers, particularly in the areas of remuneration (proper system of basic salary, bonuses and non-salary benefits) and employee's assessment - creation of clear evaluation criteria and combining them with the motivational system (mainly within the area of remuneration and development), also a particular attention should be given to the improvement of the communication and information flow, increasing the opportunities for development and promotion and better fulfilment of employees' needs and expectations. 
According to the survey, the motivation of academic teachers is affected by many different factors - it is vital to use the knowledge about them for improving the quality and efficiency of the organization. It must be remembered, that the strategy for building efficient motivational solutions in public sector is not easy. Many of them, especially in the area of remuneration, requires the systemic changes. However, it is worth to look for the opportunities for improvement with using the already existing tools and to pay attention to intangible means of recognition. It should be kept in mind, however, that in case of such motivators the commitment of the management is vital - this applies to, among others, transparent procedures and the willingness and creativity of the management.

For the higher education institutions which build their efficiency based on human factor activity, the main element generating the competitive advantage is the capital of competent and engaged academic teachers. The creation of such, requires effective motivational process. As the already existing motivational systems of the higher education institutions leave much to be desired, their improvement is worth attention in order to fulfil the main organization's objective, which is focused on work efficiency in accordance with the employees' expectations and the institution's strategy. Owing to the motivated staff, the higher education institution is able to achieve a high level of education process efficiency and quality. Creating proper working conditions may not only result in achievement of the institution's goals but also influence the positive image of the organization.

The presented results of the survey may constitute a starting point for implementation of changes in the motivational system dedicated to academic teachers of the surveyed institution and also trigger similar, in-depth survey of the analysed area in following years, in order to set trends towards motivation of the academic staff of the higher education institution.

\section{References}

Borkowska, S. (2006). Motivation and motivating // Human resources management. Creating the human capital of organization. - Warsaw: PWN. 333 p.

Buelens, M., Broeck Van den, H. (2007). An Analysis of Differences in Work Motivation between Public and Private Sector Organizations // Public Administration Review. Vol. 67. No. 1: $65: 74$

Czajka, Z. (2012). The human resources management in the public administration. Warsaw: Institute of Labor and Social Affairs. 25 p. PWN. $14 \mathrm{p}$

Długosz, D. (2006). Personnel of public administration // Public administration. - Warsaw:

Geryk Ż. (2010). Motivation in Non-public Educational Institution in Poland - Warsaw: SGH Publishing House in Warsaw. 9 p.

Hood, C. (1991). A public management for all seasons?, - Public Administration, t. 69, z. 1, 3:19 pp.

The Ministry of Science and Higher Education (2010). Human Resource Analysis in Higher Education Institutions and Rules for Full-Time Employees Allocation - Warsaw. 
Pauli, U., Sapeta, T. (2016). The use of satisfaction survey in a process of shaping employee engagement in the local administration // Shaping employee engagement and attitudes in the public sector and non-profit organizations. - Cracow: Edu-Libri Press. 30 p.

Penc, J. (1996). Motivating in management process. - Cracow: Professional Business School Press, 202, 209 p.

Pietroń-Pyszczek, A. (2004). Identification of Employees' Expectations as a Part of Motivating Process // Success in Human Resource Management. Global and local perspective. [ed.] Listwan T., - Wrocław: Prace Naukowe AE in Wrocław, no 1032, 688:696 pp.

Pietroń-Pyszczek A. (2015). Motivating Employees. Tips for managers. - Wrocław: Marina. $57 \mathrm{p}$.

Pocztowski, A. (2007). Human resources management. - Warsaw: PWE. 207:208 pp.

Sekuła, Z. (2008). Motivating to work. Theory and tools. - Warsaw: PWE. 16 p.

Stachowska, S. (2013). Motivating to work // Managing social potential of organization. [ed.] Walkowiak R., Czaplicka-Kozłowska I., Stachowska S., Kozłowski A. - Włocławek: Expol. $113 \mathrm{p}$. $191 \mathrm{p}$.

Ściborek, Z. (2014). Motivating in public organizations. - Szczytno: Police Academy Press.

Warwas I., Wiktorowicz J., Gzik M. (2017). Opinion and expectation survey of employees: university case study. Education of Economists and Managers. Vol. 1(43). 91 p. 